\title{
Prechamber selection for a two stage turbulent jet ignition of lean air-gas mixtures for better economy and emission
}

\author{
Ireneusz Pielecha ${ }^{1,{ }^{*}}$, Krzysztof Wislocki ${ }^{1}$, Wojciech Cieslik $^{1}$, and Lukasz Fiedkiewicz ${ }^{1}$ \\ ${ }^{1}$ Poznan University of Technology, Faculty of Machines and Transport, 69-965 Poznan, Poland
}

\begin{abstract}
The paper presents the results of thermodynamic and exhaust emission analyses of the combustion process using three combustion chambers. The combustion process research was performed on a single-cylinder AVL 5804 engine equipped with a dual-band compressed natural gas system supplied at different fuel pressures to the inlet channel and to the pre-chamber. Based on the performed analyses, the thermodynamic indicators of the combustion process and the emission factors were determined. Having the thermodynamic and emission analyses of the Turbulent Jet Ignition (TJI) combustion system, the prechamber was selected with the best collective features. The selection of the best chamber was made using the weighted-purpose method for average indicated pressure, $\mathrm{CO}$ and $\mathrm{NO}_{\mathrm{x}}$ emissions as well as the indicated engine efficiency, taking into account the impact factors.
\end{abstract}

\section{Introduction}

Further improvement of the combustion process requires searching for the possibility of burning lean mixtures (allowing to reduce the fuel consumption). The drive to reduce carbon dioxide emissions in fuel combustion increases the consideration given to gaseous fuels. In the stoichiometric combustion of methane (the main component of natural gas) and diesel fuel, the mass of produced carbon dioxide is: $2.75 \mathrm{~kg}$ and $3.17 \mathrm{~kg}$ per $1 \mathrm{~kg}$ of fuel burned respectively. Combustion of gaseous fuel can mean about $15 \%$ reduction of carbon dioxide emissions.

The analysis of combustion systems for lean mixtures using natural gas is carried out in relation to direct injection [1-3] or indirect injection (two-stage combustion system). A two-stage methane combustion system in the Turbulent Jet Ignition system (using the pre-chamber) is already used in F1 engines, heavy-duty vehicles and in high-capacity marine engines; currently it is also adopted for engines with small displacement volumes.

Simulation research and experimental studies of the two-stage combustion system have already been comprehensively conducted since the 1960s. Such studies are also continued today; in a rapid compression machine, such tests were performed by Gholamisheeri et al. among others [4]. A single-hole pre-chamber was used in them, and the tests were carried out with the excess air ratio of $\lambda=1.25$ for various diameters of the holes from the preliminary chamber $(2.0,2.5$ and 3.0 $\mathrm{mm})$. It has been shown that the highest flow rate is achieved at holes diameter of $2.5 \mathrm{~mm}$. The exhaust gas velocity was estimated at $100-300 \mathrm{~m} / \mathrm{s}\left(\right.$ at $\left.\operatorname{Re}=3-6 \times 10^{4}\right)$. Tests on setups with more holes from the preliminary chamber were conducted by Gentz et al. [5]. They showed a high value of fuel flow velocity from this chamber in the range of $250 \mathrm{~m} / \mathrm{s}$ when using holes with a diameter of $1.5 \mathrm{~mm}$ and an excess air ratio of $\lambda=1.25$, while for $\lambda=1.0$ the outflow velocity is much higher and amounts to about $400-500 \mathrm{~m} / \mathrm{s}$ (according the authors' estimation).

Research on the two-stage combustion (TJI) application is performed not only with methane, but also when using other fuels, such as hydrogen [6, 7], isooctane [8] and other gaseous fuels.

Currently, research on the possibilities of using direct injection of natural gas in passenger car engines is being carried out by scientific consortia within the framework of the GasOn (Gas-Only internal combustion engines) grant from Horizon 2020 [1-3]. The GasOn project aims to develop an advanced mono-fuel engine powered by compressed natural gas $(\mathrm{CNG})$. The authors of this study are also a part of these research efforts. Earlier work of the authors regarding this project was related to the dual fuel type control strategies $[9,10]$ and preliminary research on the use of the Turbulent Jet Ignition system [11].

\section{Aim and scope of research}

The use of different pre-chambers in the studies required thermodynamic analyses of the impact of their geometrical properties on the processes of charge preparation and combustion. Thus, the performed calculations included: a) thermodynamic analyses and 2) emission analyses which allow for determining the best conditions of the combustion process. Based on the results of measurements and thermodynamic calculations and the operation indicators of the engine equipped with

Corresponding author: ireneusz.pielecha@put.poznan.pl 
different variants of the pre-chamber, comparative assessment of the functional features of these prechambers became possible, in particular the assessment of the impact of 1) the size of the pre-chamber and 2) the diameter of the discharge channels for thermodynamic processes and exhaust emission of the test engine equipped with a Turbulent Jet Ignition system.

\section{Research methodology}

The combustion process research was carried out on a single-cylinder AVL5804 test engine $\left(V_{c}=0.510 \mathrm{~cm}^{3}\right)$ adapted for the two-stage TJI combustion system, and mechanically charged. The layout of the test bench and its basic structural parameters are shown in Fig. 1.

One of the test cycles was performed for three different pre-chambers with the same number of outlets (6-holes) spreading radially from the centre of the atomizer. The structural differences between the tested chambers are the diameter of the holes $(1.5$ and $2 \mathrm{~mm})$ and the various chamber volumes $\left(1.8\right.$ and $\left.2.2 \mathrm{~cm}^{3}\right)$. Analysis of the combustion process was performed for various fuel dose values injected into the pre-chamber (0.3-1.9 mg) and different values of the charge pressure (different values of the excess air ratio). The detailed sizes of the pre-chambers are included in table 1 , and the test plan in Fig. 2.

\section{Results of indicators and emissions tests}

Collective analysis of the research plan presented in Fig. 2 was performed using thermodynamic and emission indicator maps - their results are shown in Fig. 3.

The combined analyses have shown that an increase in the average indicated pressure (IMEP av) (Fig. 3a) is observed as the dose to the prechamber (qo_PC) decreases, while the excess air ratio is increased. The emission of nitrogen oxides (Fig. 3b) depends to a large extent on the excess air ratio, where the change in the dose administered to the pre-chamber is insignificant. The emission of carbon monoxide (Fig. 3c) is slightly dependent on the initial dose, and more on the excess air ratio. However, there is no clear trend indicating the most favorable value of this coefficient. The overall efficiency of the engine (Fig. 3d) determined on the basis of the indicated pressure points to the existence of a minimum of this value in the large excess air ratio values range and the lowest fuel dose supplied to the prechamber.

Thus the above analyzes have shown that the greatest benefits of using a two-stage combustion system occur at the lowest dose of fuel injected into the pre-chamber (at different $\lambda$-values). For this reason, further thermodynamic analyzes were carried out only for research points in which qo_PC $\rightarrow \min$.

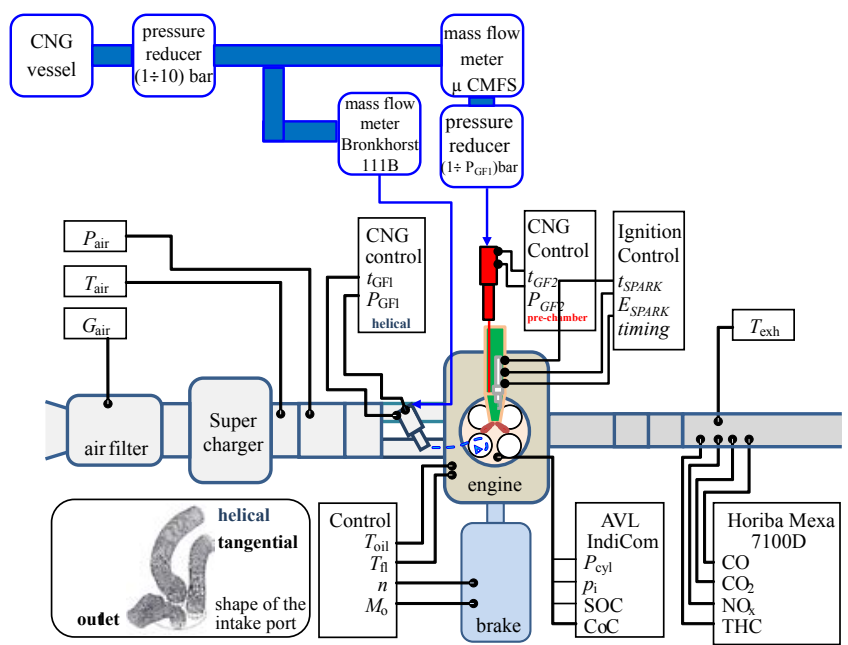

\begin{tabular}{|c|c|c|}
\hline Parameter & Unit & Value \\
\hline Engine type & - & 1-cyl., 4-valve \\
\hline$D$ & $\mathrm{~mm}$ & 85 \\
\hline$S$ & $\mathrm{~mm}$ & 90 \\
\hline$\varepsilon$ & - & 15.2 \\
\hline$P_{\text {inj }}$ & bar & 8 (inlet duct) \\
\hline$\lambda$ & - & $1.3-1.65$ \\
\hline$n$ & $\mathrm{rpm}$ & 1500 \\
\hline$C o C$ & $\mathrm{deg}$ & 8 \\
\hline$I_{i g n}$ & $\mathrm{~A}$ & 6.5 \\
\hline qo_DI & $\mathrm{mg}$ & $0.3-1.9$ \\
\hline qo_all & $\mathrm{mg}$ & 17 \\
\hline Spark plug & - & M10\&sensor \\
\hline
\end{tabular}

Fig. 1. Test bench diagram (left) and its main parameters (right).

Table 1. Prechamber characteristics in a TJI system.

\begin{tabular}{|c|c|c|c|}
\hline \multirow{2}{*}{ No. } & $V_{c h}$ & $\begin{array}{c}\text { No. of } \\
\text { nozzles }\end{array}$ & D_nozzle \\
\cline { 2 - 4 } & $\mathrm{cm}^{3}$ & - & $\mathrm{mm}$ \\
\hline 1 & 1.826 & 6 & 1.5 \\
\hline 2 & 2.287 & 6 & 2.0 \\
\hline 3 & 2.287 & 6 & 1.5 \\
\hline
\end{tabular}
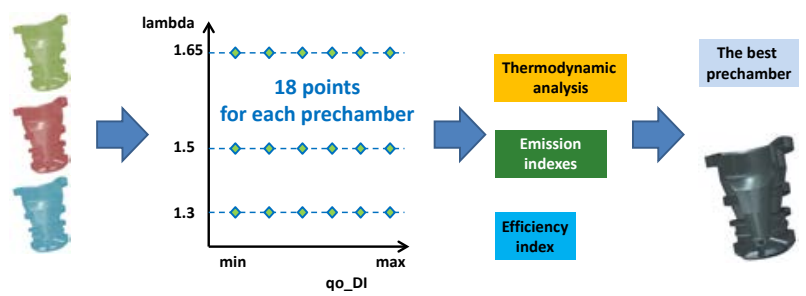

Fig. 2. Thermodynamic and emission tests plan. 

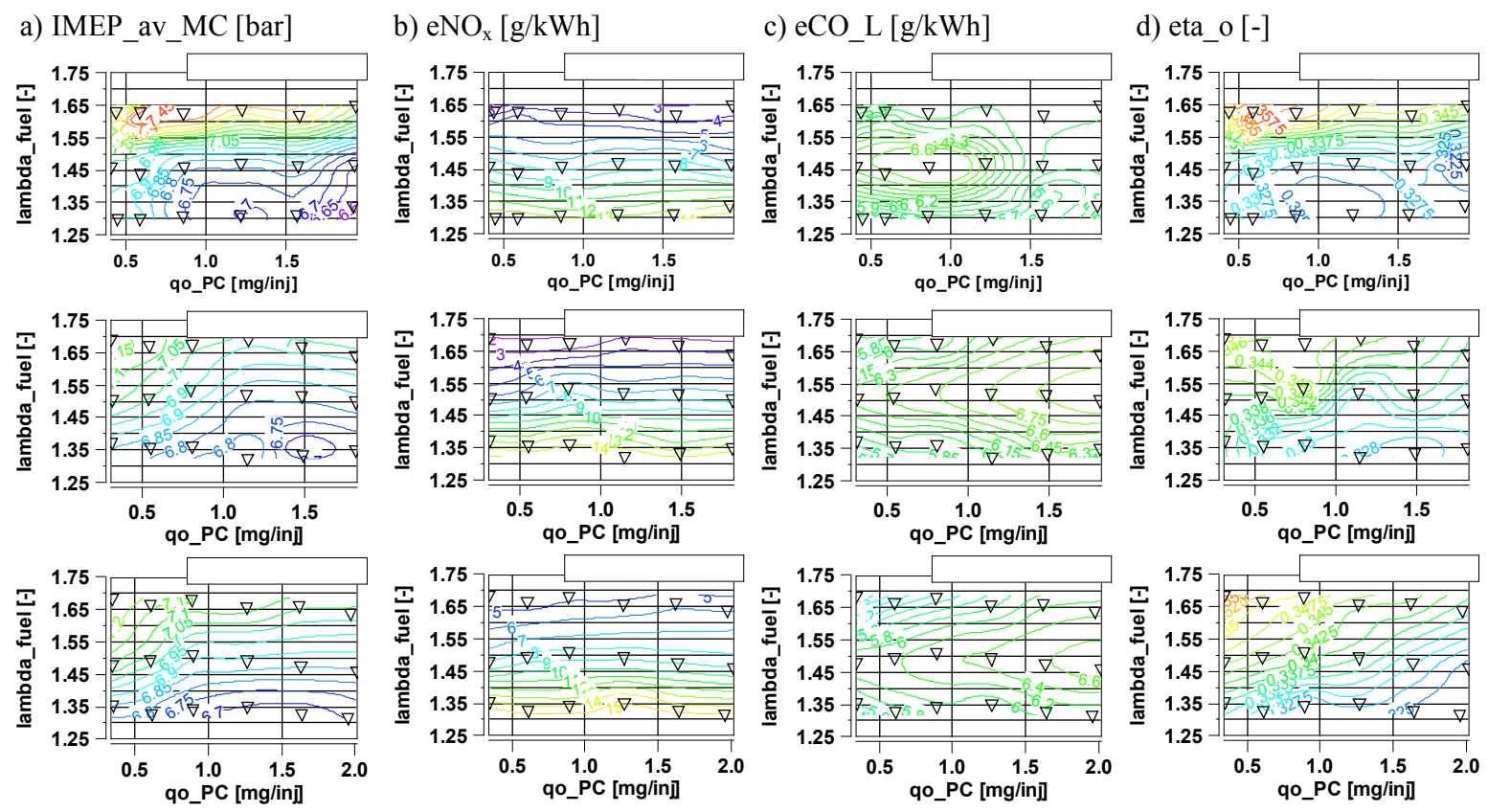

Fig. 3. Analysis of collective thermodynamic and emission indicators for the tested pre-chamber variants.

\section{Thermodynamic indicators analysis}

Detailed thermodynamic studies of the two-stage combustion system were conducted with regards to: the combustion process indicators characteristic, temperature in both chambers, the speed and amount of heat released.

The analysis of the above indicators for both chambers (pre-chamber and main chamber) indicates differences of $1 \%$ in the determined average indicated pressure. A characteristic diagnostic value is the prechamber pressure increase at the beginning of the combustion process (Fig. 4a). Analysis of the average temperature value determined using the combustion pressure in both chambers resulted only in small differences - Fig. 4b.

Slightly higher dose temperature values were recorded in the main chamber $(1882 \mathrm{~K})$ than in the prechamber $(1846 \mathrm{~K})$. These differences result from the pressure change, where the peak pressure value is also lower in the pre-chamber. Analysis of the heat release rate does not indicate significant differences in its maximum value $\left(136 \mathrm{~kJ} / \mathrm{m}^{3} \mathrm{deg}-\mathrm{PC}\right.$ and $138 \mathrm{~kJ} / \mathrm{m}^{3} \mathrm{deg}-$

a)

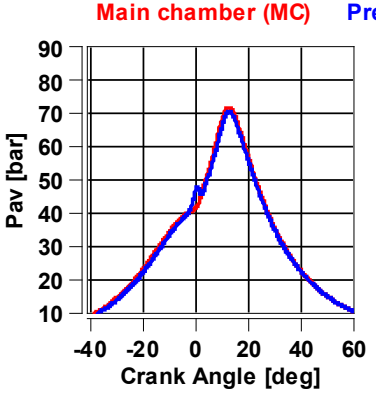

b)

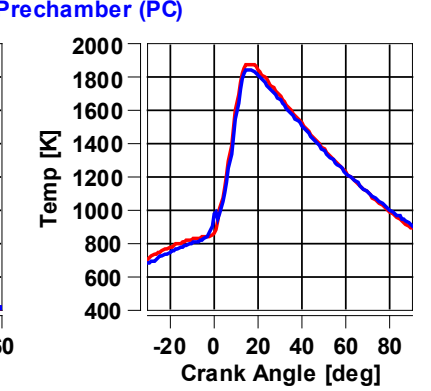

MC). A clear peak of this parameter value indicates the initiation of combustion in the pre-chamber, and its value decreases when the combustion process is transferred to the main chamber - Fig. 4c. Maximum values of the heat released are about $1362 \mathrm{~kJ} / \mathrm{m}^{3}$ (the difference between chambers is only $0.2 \%$ ). Starting the combustion process in the pre-chamber results in higher initial values of the heat released in this chamber - Fig. $4 \mathrm{~d}$; combustion process development in the main chamber results in obtaining the same values of the heat released (the analysis was carried out with reference to the specific volume and not to the total volume of the pre-chamber).

The analysis of thermodynamic indicators at $\lambda=1.65$ (Fig. 5a) was performed for the same quantities, that are shown in Fig. 4. Due to the small volume of the prechamber 1 the highest pressure increase was obtained, which did not allow reaching the maximum IMEP value (7.18 bar). The maximum value of this indicator was obtained for chamber 3 (7.30 bar). Rough engine operation $(\mathrm{CoV})$, defined as the ratio of the standard

c)

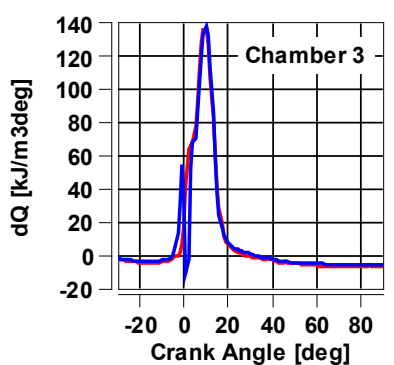

d)

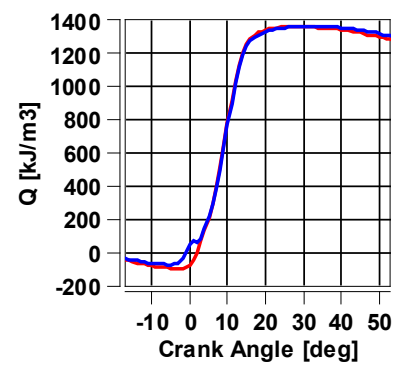

Fig. 4. Analysis of collective thermodynamic and emission indicators (operating point 6 , qo_PC=0.34 mg, $\lambda=1.65$ ): a) cylinder pressure, b) temperature, c) heat release rate, d) heat release. 
a)

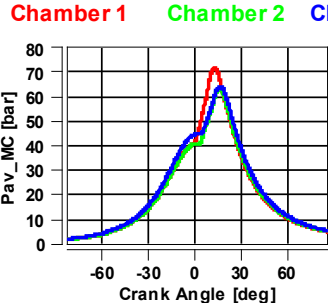

b)

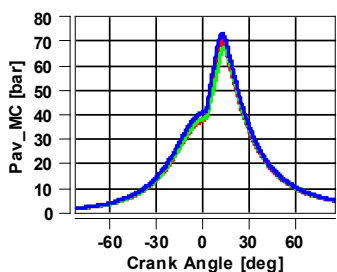

c)

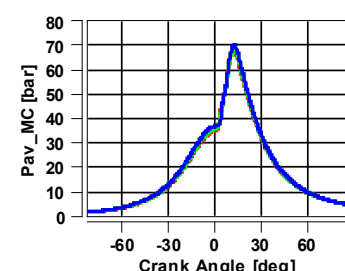

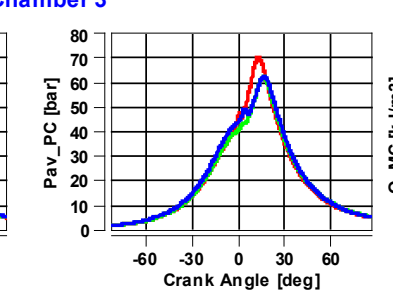
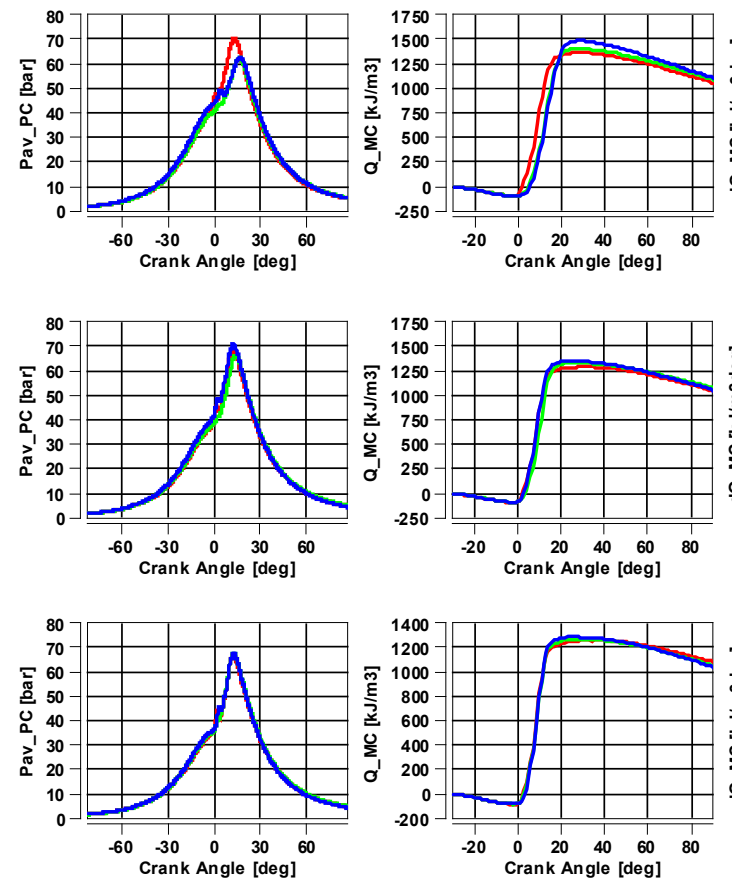
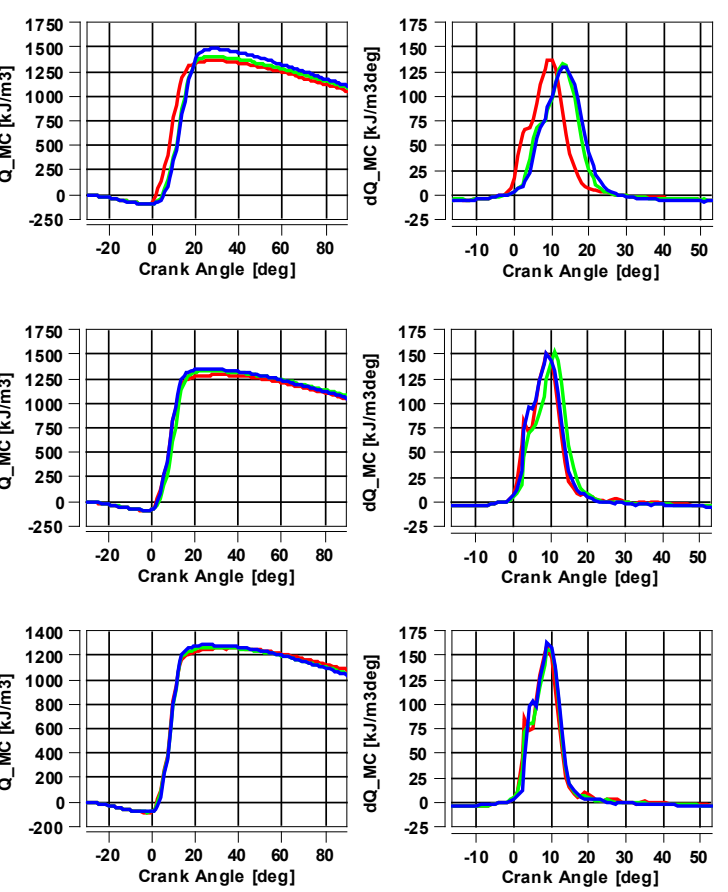

Fig. 5. Analysis of collective thermodynamic and emission indicators (operating point $6, q o \_P C=0.34 \mathrm{mg}$ ): a) $\lambda=1.65$, b) $\lambda=1.5$, c) $\lambda=1.3$

deviation $(\sigma)$ to the mean indicator value (IMEP_av ranges from $0.9 \%$ (chamber 3 ) to $1.23 \%$ (chamber 1 ). Higher pressure increase in chamber 1 initially causes a faster increase in heat release, however, the total value of the heat released is lower. This is due to the lower value of the indicated pressure during expansion.

Reducing the excess air ratio value to $\lambda=1.5$ (obtained by reducing the boost pressure) causes a slight decrease in the maximum combustion pressure (Fig. 5b). In this case, there is also a reduction in the differences in the combustion pressure characteristic and the amount and rate of heat released. The value of the IMEP indicator varies between 7.09 bar (chamber 3) and 6.98 bar (chamber 1). The engine's operation roughness coefficient is around $1 \%$. The maximum heat release rate is constant, but due to the uneven operation, the amount of heat released is greatest when using chamber 3 .

A further decrease in the boost pressure (up until $\lambda=$ 1.3 - Fig. 5c) leads to the combustion process being the same for each of the three pre-chambers. There are only slight differences at the initiation of the combustion process. This may be the result of the size of the prechamber and the diameter of the outlets. The larger volume of the pre-chamber allows for the collection of more fresh air. Such a dose during ignition, flowing through the smaller hole diameters, increases its flow rate and speed. Higher flow rates result in faster flame propagation in the engine main chamber.

\section{Pre-chamber selection}

Following methodology was accepted (for each prechamber):
- Selection of the global (for all 3 cases) min and max values for every component,

- Normalizing all absolute measured values to the relative values in the range $<0 ; 1>$ :

- max of emission - value 0 ,

- $\min$ of emission - value 1 ,

- max of IMEP and efficiency- value 1,

- min of IMEP and efficiency - value 0 ,

- Determining the totals of all quantities for all 18 operating points,

- Arbitrary selection of the impact factors $(I F)$ for every emission component, efficiency and IMEP-values $(\Sigma=$ 1),

- Calculation of the products of sums and impact factors,

- Determining the resulting sums.

Normalization of the measured quantities (Norm) was performed in the range $<0 ; 1>$. This means that each variable (IMEP, e_CO_L, e_NOx, eta_o) in a set of 54 test points ( 18 points $\times 3$ chambers) has been assigned a value in the range described above (in this set there is only one value 1 - global maximum and only one value 0 - local minimum).

It follows that the Ind indicator value is calculated as:

$$
\operatorname{Ind}(\mathrm{Ch})=\sum_{\mathrm{Ch}=1}^{3} \sum_{\mathrm{j}=1}^{18} \operatorname{Norm}(\operatorname{Ind}(\mathrm{Ch}))
$$

where $C h$ is the pre-chamber, $j$ - the number of the tested operating point.

The procedure presented here made it possible to assign numerical values to individual test chambers. An importance weight of 0.25 was applied to each measuring quantity.

A total value of the indicator $(O v)$ describing the given pre-chamber was determined as the product of the 
impact factor $(I F)$ and the value of the indicator (Ind) in the form:

$$
O v(C h)=\sum_{i=1}^{4} I F_{i} \times \operatorname{Ind}_{i}
$$

where $i$ is the analysed indicator (eCO_L, eta_o, eNOx and IMEP).

Using the described procedure for the best chamber selection, the obtained results were combined in Table 2.

Table 2. Values of the tested parameters of pre-chambers assuming the same impact factor $(I F=0.25$ for each measured parameter).

\begin{tabular}{|c|c|ccc|}
\hline $\begin{array}{c}\text { Factor } \\
(I F)\end{array}$ & Indicator $($ Chd $)$ & 1 & 2 & 3 \\
\hline 0.25 & eCO_L & 6.41 & 5.52 & 7.95 \\
0.25 & eta_o & 6.60 & 7.76 & 7.85 \\
0.25 & eNOx & 9.14 & 9.85 & 7.73 \\
0.25 & IMEP & 7.92 & 6.53 & 7.17 \\
\hline \multicolumn{1}{|c|}{ Overall $(O v)$} & 7.52 & 7.42 & 7.67 \\
\cline { 2 - 5 }
\end{tabular}

The comparison presented in Table 2 shows that the best choice with the criteria applied is a chamber characterized by a large volume $\left(V_{c h}=2.287 \mathrm{~cm}^{3}\right)$, and a small outlets diameter $(D=1.5 \mathrm{~mm})$ assuming simple outflow channels.

\section{Conclusions}

The performed analyses allowed for formulating the following conclusions:

- a two-stage combustion system enables combustion of lean gas-air mixtures with an excess air ratio far exceeding the value of $\lambda=1$ (up to approx. 1.8). - $\quad$ the pre-chamber size and the number of holes are very important when burning lean mixtures. A small volume of the pre-chamber accelerates the combustion process, however, it does not lead to obtain the maximum average indicated pressure (IMEP) value. When reducing the excess air ratio, this tendency decreases.

- $\quad$ when using methane-air mixtures with $\lambda=1.3$ and less, the impact of the chamber size and the diameter of the holes is negligible in relation to the average thermodynamic processes. A similar effect of the excess air ratio was noted for the emissions of $\mathrm{CO}$ and $\mathrm{NO}_{\mathrm{x}}$.

According the analysis performed in the research the optimal results were achieved for bigger volume of prechamber and smaller outlet channels, probably because of higher mixture spray energy and better activation of lean mixture in main chamber.

\section{Acknowledgements}

The research presented in this paper was performed within the European Research Project Horizon 2020, grant agreement No. 652816, Gas-Only Internal Combustion Engines. The authors wish to thank the EU for funding the work and express their acknowledgements to all persons, who have had their contribution in this study and the laboratory works.

\section{References}

1. M. Baratta, D. Misul, P. Goel, D. Laurenzano, B. Lecointe, L. Rouleauet, F. Ravet, P. Christou, SAE Technical Paper 2018-01-1142 (2018)

2. M. Ferrera, SAE Technical Paper 2017-24-0059 (2017)

3. U. Kramer, T. Lorenz, C. Hofmann, H. Ruhland, R. Klein, C. Weber, SAE Technical Paper 2017-010776 (2017)

4. M. Gholamisheeri, I.S. Wichman, E. Toulson, Combust. Flame 183 194-206 (2017)

5. G. Gentz, B. Thelen, M. Gholamisheeri, P. Litke, A. Brown, J. Hoke, E. Toulson, Appl. Therm. Eng. 81 399-411 (2015)

6. S. Biswas, L. Qiao, Appl. Therm. Eng. 132 102-114 (2018)

7. H. Wu, L. Wang, X. Wang, B. Sun, Z. Zhao, C. Lee, F. Liu, Int. J. Hydrogen Energ. 43, 16 8116-8126 (2018)

8. G. Gentz, M. Gholamisheeri, E. Toulson, Appl. Energ. 189 385-394 (2017)

9. I. Pielecha, K. Wisłocki, W. Cieślik, P. Borowski, W. Bueschke, M. Skowron, SAE Technical Paper 2016-01-2305 (2016)

10. I. Pielecha, K. Wisłocki, W. Cieślik, W. Bueschke, M. Skowron, Ł. Fiedkiewicz, Appl. Therm. Eng. 132 188-195 (2018)

11. I. Pielecha, W. Bueschke, W. Cieślik, M. Skowron, MATEC Web of Conferences, 118 00010-1-0001010 (2017) 